\title{
Feasibility of protein A for the oriented immobilization of immunoglobulin on silicon surface for a biosensor with imaging ellipsometry
}

\author{
Zhanhui Wang, Gang Jin* \\ National Microgravity Laboratory, Institute of Mechanics, Chinese Academy of Sciences, \\ 15, Bei-Si-Huan West Road, Beijing 100080, PR China
}

Received 7 April 2003; received in revised form 7 April 2003; accepted 29 May 2003

\begin{abstract}
The feasibility of using protein A to immobilize antibody on silicon surface for a biosensor with imaging ellipsometry was presented in this study. The amount of human IgG bound with anti-IgG immobilized by the protein $\mathrm{A}$ on silicon surface was much more than that bound with anti-IgG immobilized by physical adsorption. The result indicated that the protein A could be used to immobilize antibody molecules in a highly oriented manner and maintain antibody molecular functional configuration on the silicon surface. High reproducibility of the amount of antibody immobilization and homogenous antibody adsorption layer on surfaces could be obtained by this immobilization method. Imaging ellipsometry has been proven to be a fast and reliable detection method and sensitive enough to detect small changes in a molecular monolayer level. The combination of imaging ellipsometry and surface modification with protein $\mathrm{A}$ has the potential to be further developed into an efficient immunoassay protein chip.
\end{abstract}

(C) 2003 Elsevier B.V. All rights reserved.

Keywords: Protein A; Oriented immobilization; Protein chip; Imaging ellipsometry

\section{Introduction}

Imaging ellipsometry is an optical reflection-based technique for thin-film and surface characterization [1]. A biosensor based on it was developed to investigate protein

* Corresponding author. Tel.: +86-106-262-1297; fax: +86-106-256-1284

E-mail address: gajin@imech.ac.cn (G. Jin). 
adsorption and interactions. Compared to other solid-phase methods currently used, such as enzyme-linked immunosorbent assay (ELISA), immunofluorescence and radioimmunoassay, this method has the advantage of not involving any labeling of the reactant, thus avoiding disturbances from conjugated markers or handling with radioactive materials. This allows the application in a broad range of different biological systems. Imaging ellipsometry is an enhancement of standard single-beam ellipsometry which uses a CCD camera to image the ellipsometric response of a large area on sample surface. This feature allows multisensing, and high throughout systems can be developed based on it.

An antibody is a protein that binds to the target antigen with extremely high specificity upon the affinity of antigen-antibody. Because of their high specificity, immobilized antibodies on various solid-phase surfaces have been widely used in many fields such as purification of materials, diagnostic immunoassays and sensing [2]. In the present study, we investigated the immobilization of antibody on silicon surface. Silicon is the most frequently used material as a substrate in electronic devices and a highly suitable surface for ellipsometry experiments [3]. One of the most important aspects in biosensor development with high sensitivity is related to the immobilization of antibody and the maintenance of functional configuration on the substrate surface. Due to steric hindrance and random orientation of the antibody molecules on the solid-phase surface, the binding activity of antibody immobilized directly on the solid-phase surface is usually less than that of soluble antibody [4]. In order to overcome the problem, protein A was used to modify silicon surface for antibody immobilization. Protein A was a cell wall component of Staphylococcus aureus that specifically bound to the $\mathrm{F}_{\mathrm{c}}$ portion of immunoglobulin from many mammals [5], while leaving the $\mathrm{F}_{\mathrm{ab}}$ regions available for antigen binding. It has been successfully used to orient the antibodies in a variety of immunoassays, such as magnetic beads and ELISA [6,7]. The immunoassays mentioned above were achieved almost by labeling. Imaging ellipsometry could be performed as a label-free technique. The reproducibility of the immobilization and the homogeneity of antibody adsorption layer on surfaces were key elements for high sensitivity. It was investigated that the feasibility of silicon surface coated with protein A to immobilize antibody as an alternative to the direct immobilization by adsorption for a biosensor with imaging ellipsometry.

\section{Materials and methods}

\subsection{Materials}

Human immunoglobulin $\mathrm{G}(\mathrm{IgG})$, goat anti-IgG, bovine serum albumin (BSA) and protein A were purchased from Sigma (USA). Chemicals used for the buffer preparation were all in analytical grade or better. Silicon wafers were purchased from General Research Institute for Nonferrous Metals.

\subsection{Buffer}

Phosphate-buffered saline (PBS; $10 \mathrm{mM}$ phosphate, $0.1 \mathrm{M} \mathrm{NaCl} \mathrm{pH} \mathrm{7.2)} \mathrm{was} \mathrm{prepared}$ in deionized water. 


\subsection{Preparation of dichlordimethylsilane-modified silicon wafers}

Polished silicon wafer was chosen as substrate here. The silicon wafers were cut into rectangles about $1 \times 2 \mathrm{~cm}$. The wafer surface was washed in solution $\left(30 \% \mathrm{H}_{2} \mathrm{O}_{2}: 98 \%\right.$ $\mathrm{H}_{2} \mathrm{SO}_{4}=1: 3 \mathrm{v} / \mathrm{v}$ ) for $30 \mathrm{~min}$. The solution not only removes contaminants of the silicon surface, but also improves the number of silanol groups on the surface, thus making the surface hydrophilic. After rinsed in deionized water and ethanol, the washed surfaces were incubated in a mixture of dichlordimethylsilane (DDS) $(20 \%, \mathrm{v} / \mathrm{v})$ and $\mathrm{C}_{2} \mathrm{HCl}_{3}(80 \%)$ for 5 min, followed by rinsing in sequence with ethanol and $\mathrm{C}_{2} \mathrm{HCl}_{3}$. Through reaction of dichlordimethylsilane with silanol groups of the surface, $-\mathrm{Si}\left(\mathrm{CH}_{3}\right)_{2}$ was immobilized covalently, forming a layer of densely packed methyl groups on silicon dioxide layer and making the surface highly hydrophobic. Normally, the natural silicon dioxide layer and the silanization layer are considered as a uniform background due to the fact that they have almost the same optical characters which is kept invariable during the measurement period.

\subsection{Immobilization of anti-IgG on DDS-modified surface}

Hydrophobic silicon wafer was placed into $0.1 \mathrm{mg} / \mathrm{ml}$ anti-IgG solution and allowed the incubation for different lengths of time. After which, the wafers were rinsed with deionized water and dried with a stream of nitrogen. The amount of surface-bound antiIgG was determined by imaging ellipsometry. Before incubated with human IgG, the surface immobilized with anti-IgG was blocked with $1 \%$ bovine serum albumin solution (PBS) for $30 \mathrm{~min}$.

\subsection{Oriented immobilization of anti-IgG on protein A-modified surface}

The DDS-modified surface was first treated with protein A modification by immersion in $0.1 \mathrm{mg} / \mathrm{ml}$ protein A solution until the saturation surface concentration of protein A was obtained. The protein A-modified surface was then blocked with 1\% bovine serum albumin solution (PBS) for $30 \mathrm{~min}$. The surface was incubated in $0.1 \mathrm{mg} / \mathrm{ml}$ anti-IgG solution for different length of time. After rinsed with deionized water and dried with nitrogen, the surface concentration of surface-bound anti-IgG was determined by imaging ellipsometry.

\subsection{Binding of the immobilized anti-IgG with $\operatorname{Ig} G$}

Surfaces immobilized with anti-IgG by physical adsorption (on DDS-modified surfaces) and protein A (on protein A-modified surfaces) were inserted into the $0.05-\mathrm{mg} / \mathrm{ml}$ solution of human $\mathrm{IgG}$ in PBS for $30 \mathrm{~min}$. After being rinsed and dried, the surface concentration of surface-bound human IgG was measured with imaging ellipsometry.

\subsection{Imaging ellipsometry}

The experiments were carried out with an imaging ellipsometry setup developed in our laboratory. Ellipsometry is an optical, reflection-based technique that uses polarized light to determine the optical properties of a sample. It is a powerful tool for optical 
characterization of surfaces and thin films and very sensitive to small changes in the optical parameters with a sub-nanometer resolution that can be achieved in bio-affinitybased sensing. As an optical technique, ellipsometry is nondestructive and can be used in any environment that allows optical access to the sample.

Imaging ellipsometry is an enhancement of traditional ellipsometry which uses a CCD camera to image the ellipsometry response of a larger area on the sample surface. In a traditional ellipsometer, the probe beam is focused on a small spot on the sample. The reflected light is detected with a single-channel detector such as a photomultiplier or a photodiode. The ellipsometry signal is measured by null ellipsometry which is based on an instrument where the polarizing elements (polarizer and analyzer) are rotated until the signal at the detector is zero (null). The optical parameters can then be deduced from the angular positions of the polarizer and analyzer. For imaging ellipsometry, which is used to detect a large-area sample with lateral distribution in layer thickness, null ellipsometry could not be carried out over the entire surface simultaneously due to the fact that different areas will yield different polarization changes. A possible solution is to use off-null mode in an ordinary null ellipsometer. The optical components in the system are adjusted to fulfill the null conditions on a silicon wafer without adsorbed layers, and the off-null ellipsometric principle is used to measure the adsorption layer thickness [8]. Under this condition, the detected intensity $I$ is related to the thickness $(d)$ of the layer according to

$$
I=k d^{2}
$$

where $k$ is a constant. The absolute thickness of layer can be obtained by a traditional ellipsometer, and $k$ can be deduced from the above equation.

The basic experimental setup used in this study was a conventional polarizercompensator-sample-analyzer null ellipsometer. The light source was a Xenon lamp, and a specific collimating system was used to provide an expanded parallel probe beam with a diameter of about $25 \mathrm{~mm}$. The beam passed through a polarizer and a compensator (a quarter wave plate) and finally onto the sample at an incident angle of $75^{\circ}$. An optical filter at $633 \mathrm{~nm}$ wavelength was placed in the incident optical passage to select wavelength in order to increase the ellipsometric contrast of images. The reflection beam passed through an analyzer and an imaging lens with a spatial filter located at its focus plane, and then the ellipsometric image was focused on a sensing area of the CCD camera. A digital image was grabbed by and stored in a computer with a grayscale format ( 8 bits, $0-255$ grayscale) for further evaluation by an image-processing program.

The thickness of biomolecular layers was calibrated with an ellipsometer of rotating analyzer type (SE 400, SENTECH, Germany) equipped with a $\mathrm{He}-\mathrm{Ne}$ laser $(\lambda=632.8$ $\mathrm{nm})$. The measurements were carried out at an angle of incidence of $70^{\circ}$.

\section{Results and discussion}

\subsection{Immobilization of anti-IgG}

The feasibility of using protein A to immobilize antibody on silicon surface for imaging ellipsometry was investigated using a model interaction between human IgG and anti-IgG. 
The surface concentration, the reproducibility of immobilization and the homogeneity of adsorption antibody layer on surface are important factors to obtain high sensitivity for the biosensor with imaging ellipsometry.

Silicon surfaces modified with DDS and protein A were used as the two kinds of surfaces to immobilize the anti-IgG. The surface modified with DDS was highly hydrophobic, and anti-IgG was immobilized on the surface by physical adsorption. Hydrophobic interaction was the major interaction that drove the adsorption of antiIgG. Anti-IgG was also immobilized on protein A-modified surface mainly via the specific binding activity between protein $A$ and $F_{c}$ fragment of anti-IgG. The kinetics of the antiIgG coupling on the DDS- and protein A-modified surfaces were shown in Fig. 1. The initial adsorption rate of anti-IgG on the DDS-modified surface was higher than that on the protein A-modified surface. The adsorption of anti-IgG reached its saturation after about $1500 \mathrm{~s}$ on both DDS- and protein A-modified surfaces, and the final thickness of anti-IgG layer on DDS-modified surface was higher than that on protein A-modified surface. The saturated monolayers of anti-IgG on DDS- and protein A-modified surfaces were shown in Fig. 2. The images in three dimensions were transformed from grayscale format according to the principle that the intensity in image is proportional to the square of the thin-layer thickness.

The absolute thicknesses of saturated layers of anti-IgG on DDS- and protein Amodified surfaces were measured by conventional ellipsometer. The relationship between surface concentration and layer thickness was surface concentration $\left(\mathrm{ng} / \mathrm{mm}^{2}\right) \approx K \times d$ (nm), where $K \approx 1.2$ [9]. According to the equation, the surface concentrations were obtained and listed in Table 1. The surface concentration of anti-IgG on protein Amodified surface was less than that on DDS-modified surface. The amount of protein A molecules and steric hindrance may be the reasons for the difference.

In order to evaluate the reproducibility of anti-IgG immobilization via protein $A$ on silicon wafer, immobilization experiments were carried out at the same conditions for five

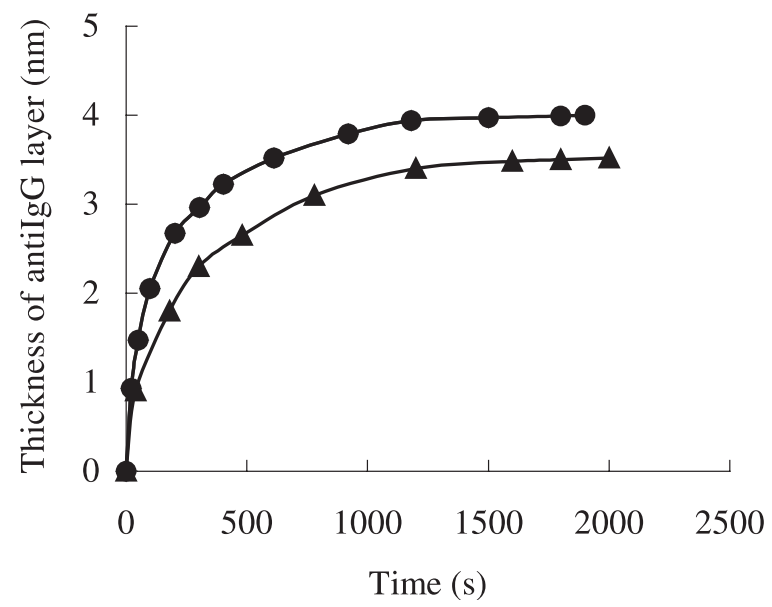

Fig. 1. Kinetics of the coupling of anti-IgG to DSS- $(\bullet)$ and protein A ( $\boldsymbol{\Delta})$-modified surfaces. 

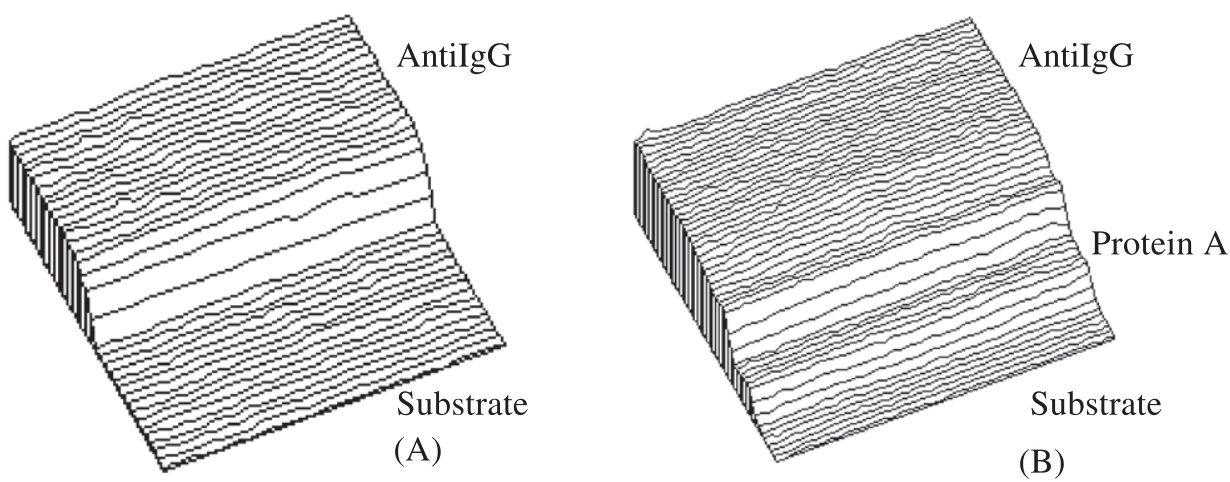

Fig. 2. (A) The saturated layer of anti-IgG formed by physical adsorption on the DDS-modified silicon surface. (B) The saturated layer of anti-IgG formed by affinity between anti-IgG and protein A on the silicon surface modified with protein A.

times. The thicknesses of anti-IgG layer immobilized by protein A were measured by imaging ellipsometry and listed in Table 2 . The data indicated that the high reproducibility could be obtained by this immobilization method.

The amount of protein bound on surface is deduced from the thickness of protein layer measured directly by imaging ellipsometry without label, so the protein layer's distribution on surface affects the measure accuracy. The homogenous protein layer can guarantee to get high-quality measure result. Five different areas on anti-IgG layer were chosen randomly to evaluate the homogeneity of the anti-IgG layer immobilized by protein $\mathrm{A}$. The results measured by imaging ellipsometry were listed in Table 3. The result illuminated that the anti-IgG layer immobilized by protein A was very homogenous.

\section{2. $\operatorname{Ig} G-$ anti-IgG interaction}

Human IgG was used as a model antigen to test the activity of anti-IgG molecules that immobilized on surfaces. The surfaces with anti-IgG immobilized by physical adsorption and protein A binding were placed into human IgG solution with the same concentration for the same length of incubation time. The results were shown in Fig. 3A and B, respectively. The height of biomolecular layers in $3 \mathrm{D}$ image was proportional to the surface concentration according to imaging ellipsometry principle. Fig. 3A showed the result of human IgG bound with anti-IgG immobilized by physical adsorption. The height

Table 1

The thickness of anti-IgG layer and surface concentration of anti-IgG on surfaces modified with DDS and protein A

\begin{tabular}{lll}
\hline & $\begin{array}{l}\text { DDS-modified } \\
\text { surface }\end{array}$ & $\begin{array}{l}\text { Protein A-modified } \\
\text { surface }\end{array}$ \\
\hline anti-IgG layer thickness $(\mathrm{nm})$ & 4.10 & 3.60 \\
Surface concentration $\left(\mathrm{ng} / \mathrm{mm}^{2}\right)$ & 4.92 & 4.32 \\
\hline
\end{tabular}


Table 2

The reproducibility of the anti-IgG bound on protein A-modified surface

\begin{tabular}{lc}
\hline Experiment & $\begin{array}{l}\text { Thickness of } \\
\text { layer (nm) }\end{array}$ \\
\hline 1 & 3.68 \\
2 & 3.55 \\
3 & 3.71 \\
4 & 3.57 \\
5 & 3.62 \\
\hline
\end{tabular}

of human IgG layer was very low, indicating that only a little human IgG was bound by anti-IgG on the surface. The result of human IgG bound with anti-IgG immobilized by protein A was shown in Fig. 3B. It is significant to note that the height of human IgG layer was much larger than that in Fig. 3A, though the surface concentration of anti-IgG immobilized by protein A was less than that by physical adsorption. To estimate the amount of human IgG bound on surfaces, ellipsometer was used to measure the thickness of IgG layer. The surface concentration of IgG in Fig. $2 \mathrm{~B}$ was $4.13 \mathrm{ng} / \mathrm{mm}^{2}$, about five times higher than that in Fig. 3A. The result indicated that anti-IgG immobilized by protein A maintained higher binding activity to human IgG than that immobilized by physical adsorption.

Attachment of antibody on silicon surface can be achieved by simple physical adsorption, but the immobilized antibody maintains low biological activity, just like the result of Fig. 3A. One of the main reasons for this reduction of binding activity is that the active site is hindered or even blocked by the linkage to the solid surface. Another possible reason is attributed to the random orientation of the active site on the solid surface [4]. Oriented immobilization of biologically active antibody can overcome these problems. Its advantages are good steric accessibilities of active binding sites and uniform orientation of active sites. In this study, anti-IgG was oriented and immobilized on the silicon surface by protein A. Protein A has the ability to bind to the $F_{c}$ portion of IgG. It is composed of five subunits, each with its own $F_{c}$ receptor, although three of these receptors become inactive when the molecule is immobilized [5]. If protein A is applied as a coating to solid surface, its $F_{c}$ receptors become sites of attachment on which the antibody can be immobilized. This mode of immobilization results in the uniform orientation of the antigen-binding sites, $\mathrm{F}_{\mathrm{ab}}$ variable regions, up from the surface, well accessible for interaction with the antigen, maximizes the antigen-binding capability of the antibody. In addition, the protein A molecule can serve as a spacer arm for the immobilized antibody, thus preventing

Table 3

The homogeneity of the anti-IgG layer formed on protein A-modified surface

\begin{tabular}{ll}
\hline Area & $\begin{array}{c}\text { Thickness of } \\
\text { layer }(\mathrm{nm})\end{array}$ \\
\hline 1 & 3.58 \\
2 & 3.61 \\
3 & 3.56 \\
4 & 3.63 \\
5 & 3.60 \\
\hline
\end{tabular}



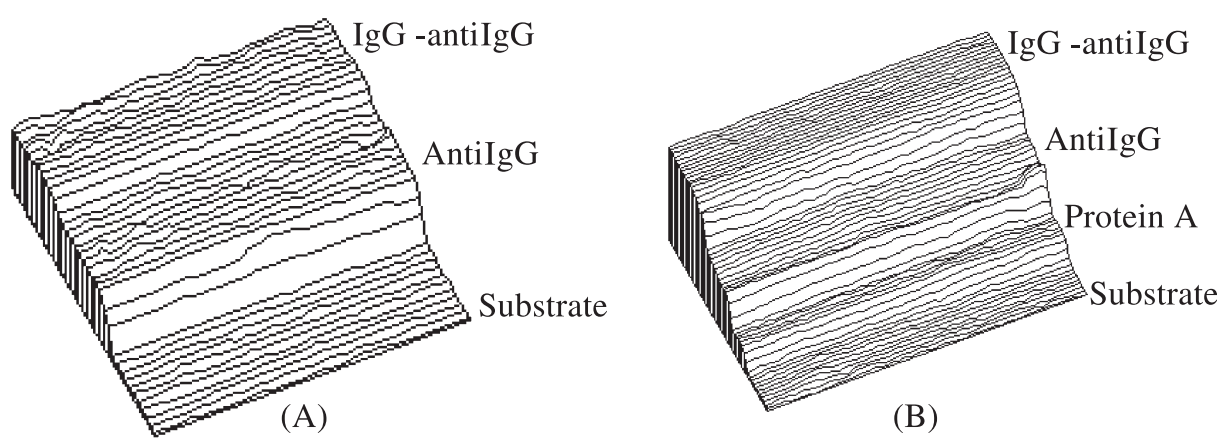

Fig. 3. (A) Human IgG bound with anti-IgG immobilized by physical adsorption on silicon surface; (B) human IgG bound with anti-IgG oriented immobilized by protein A on silicon surface. The amount of human IgG bound on surface modified with protein A was much more than that on DDS-modified surface.

antibody linkage to surface and making the antibody molecule bind with antigen flexibility.

\section{Conclusions}

The feasibility of using protein A to immobilize antibody on silicon surface for the biosensor with imaging ellipsometry has been demonstrated in this study. The anti-IgG immobilized by the protein A on silicon surface could bind human IgG effectively, which indicated that the protein A could be used to immobilize antibody molecules in a highly oriented manner and maintain antibody molecular functional configuration on the silicon surface very well. The reproducibility of amount of antibody immobilization and the homogeneity of adsorption antibody layer on surface is able to meet the requirement of the biosensor. Protein A can bind selectively the $\mathrm{F}_{\mathrm{c}}$ regions of numerous mammalian IgG. Thus, the silicon surface modified with protein A can be used to immobilize many kinds of antibodies, increasing the versatility of the biosensor with imaging ellipsometry.

The results in this study also showed that imaging ellipsometry was a fast and reliable detection method and sensitive enough to detect small changes on the molecular monolayer level. Measurements can be performed directly without requiring any special treatment. The combination of imaging ellipsometry and surface modification with protein $\mathrm{A}$ has the potential to be further developed into a sensitive immunoassay protein chip.

\section{Acknowledgements}

The National Natural Science Foundation of China and Chinese Academy of Sciences are acknowledged for their support. 


\section{References}

[1] Jin G, Tengvall P, Lundstrom I, Arwin H. A biosensor concept based on imaging ellipsometry for visualization of biomolecular interactions. Anal Biochem 1995;232:69-72.

[2] Lin JN, Herron J, Andrade JD, Brizgys M. Characterization of Immobilized antibodies on silica surfaces. IEEE Trans Biomed Eng 1988;35:466-71.

[3] Elwing H. Protein absorption and ellipsometry in biomaterial research. Biomaterials 1998;19:397-406.

[4] Kanno S, Yanagida Y, Haruyama T, Kobatake E, Aizawa M. Assembling of engineered IgG-binding protein on gold surface for highly oriented antibody immobilization. J Biotechnol 2000;76:207-14.

[5] Turkova J. Oriented immobilization of biologically active proteins as a tool for revealing protein interactions and function. J Chromatogr B 1999;722:11-31.

[6] Widjojoatmodjo MN, Fluit AC, Torensma R, Verhoef J. Comparison of immunomagnetic beads coated with protein-A, protein-G or goat anti-mouse immunoglobulins - applications in enzymes immunoassays and immunomagnetic separations. J Immunol Methods 1993;165:11-9.

[7] Ngai PKM, Ackermann F, Wendt H, Savoca R, Bosshard HR. Protein-A antibody-capture ELISA(pace) — an ELISA format to avoid denaturation of surface-adsorbed antigens. J Immunol Methods 1993;158:267-76.

[8] Jin G, Jansson R, Arwin H. Imaging ellipsometry revisited: developments for visualization of thin transparent layers on silicon substrates. Rev Sci Instrum 1996;67:2930-6.

[9] Stenberg M, Nygren H. The use of the isoscope ellipsometer in the study of adsorbed proteins and biospecific binding reactions. J Phys 1983;44:83-6. 